\title{
The Development of Cardiovascular Mortality in Finland from 1951 to 1978
}

\author{
TAPANI VALKONEN \\ Professor
}

MARJA-LIISA NIEMI

M.A.

Department of Sociology

University of Helsinki

\section{Introduction}

One of the most puzzling aspects of the development of mortality in industrialized countries has been the irregularity of the changes in male mortality since World War II. The death rates among adult men rose or stopped declining in several countries in the 1960's. On the other hand, a clear decline has been observed in some of these countries in the late 1960's and in the 1970's. The changes in total male mortality seem to have been closely associated with changes in mortality from cardiovascular diseases, among which ischaemic heart disease (coronary heart disease) is dominant. The factors that have caused these changes are, however, not well known. Adult female mortality has, in general, declined in developed countries (Ovcarov \& Bystrova 1978; Havlik \& Feinleib 1979).

This article describes the development of total mortality and cardiovascular mortality among the middle-aged (35-64 years old) population of Finland. The study covers cardiovascular mortality during the period $1951-78$ and total mortality during the period $1951-80$. The analysis especially attempts to shed light on the nature and the determinants of the fluctuations in the male cardiovascular mortality. The study is based on mortality data for the whole country, for urban and rural municipalities and for the provinces of Finland. Possible causes of the changes in cardiovascular mortality are discussed in the last part of the paper. ${ }^{1}$

1 More detailed results than reported here have been published in Finnish in Valkonen \& Niemi 1980. 


\section{Data and methods}

The data on the number of deaths by sex, five-year age group, cause of death, rural-urban division and province as well as on the relevant mean populations were obtained from published and unpublished tabulations of the Central Statistical Office of Finland. Age-standardized death rates for the agegroup 35-64 years were calculated by the direct method using the stationary population from the life tables of Finland for the period 1966-70 as standard population.

In addition to mortality from all causes, mortality from cardiovascular diseases (diseases of the circulatory system) are studied in this article. Changes in the cause-of-death classification and in the practice of death certificate coding are not as problematic here as in studies dealing with more specific causes of death. In this study cardiovascular diseases include "diseases of the circulatory system" (A79-A86) plus "vascular lesions affecting the central nervous system» (A70) in the 6th and 7th revisions of the International Classification of Diseases, which were used in Finland from 1951 to 1968. Since 1969 the 8 th revision of the ICD has been used, and cardiovascular diseases in 1969-1978 include »diseases of the circulatory system» (A80-A88).

The rural-urban distinction used in the study is based on the administrative division of municipalities into cities and rural municipalities. Several rural municipalities have become cities in the 1960's and 1970's. No attempt has been made in this study to keep the division of municipalities constant. This may lead to some artificial narrowing of urban-rural differences.

\section{Mortality in the whole country since 1951}

Figure 1 shows clearly that the development of age-standardized total mortality of men has been different from that of women: female mortality declined almost linearly during most of the whole 30 year period, whereas there was a 9 per cent increase in male mortality from 1959 to 1969 . The decline of male mortality from 1969 to 1980 was considerable, 26 per cent. The decline was, however, still greater (32 per cent) among females during the same period. As mentioned before, the irregularity of the development of male mortality is not a unique feature of Finland.

Besides the differences in the trends, figure 1 also reveals another malefemale difference: year to year fluctuations seem to have been more pronounced in male than in female death rates. The fluctuations in male mortality are considerable in the mid-1950's and around 1970.

Figures 2 and 3 indicate that both the increase in the 1960's and the rapid decline in the 1970's in male mortality were due to changes in mortality from cardiovascular diseases. The lowest male cardiovascular death rate was reached in 1957. After that year the death rate rose by 19 per cent in five years. 
Figure 1. Age-standardized mortality (per 100,000) from all causes among males and females aged $35-64$ years in Finland in $1951-80$.

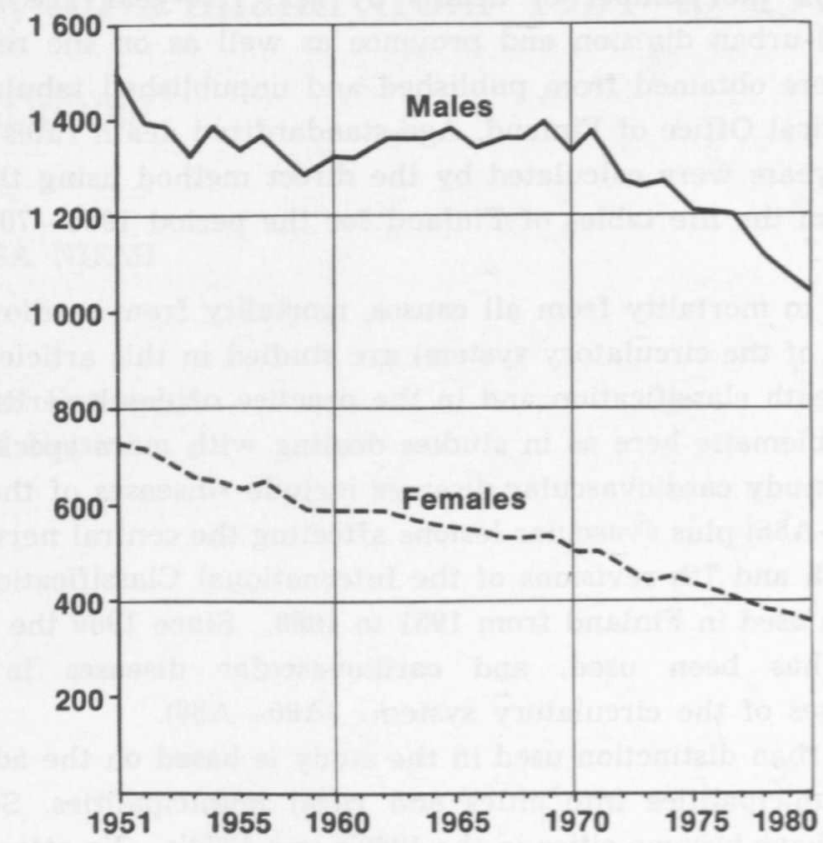

There is no exceptional decline in mortality from other diseases than cardiovascular diseases during this period (the high mortality in 1957 was due to an epidemics, which seem to have influenced even cardiovascular mortality. For the main part of the rise of cardiovascular mortality was real and not caused by changes in death certificate coding.

From 1965 to 1969 there was no change in male cardiovascular mortality The yearly fluctuations after 1969 are connected with the timing of influenza epidemics, which seem to have influenced even cardiovascular mortality. For example, the peak in cardiovascular mortality in 1971 is connected with a serious epidemic of influenza in December 1971: there were 33 per cent more cardiovascular deaths (in the whole population) in December 1971 than in December 1972, when there was no epidemic of influenza.

The yearly fluctuations of mortality make it difficult to state exactly when, in the period 1969-1971, the decline of cardiovascular mortality actually started. In any case there was a clear decline in mortality from about the year 1970 to 1975 . After a two year stagnation the decline seems to have continued in 1978 .

The fluctuations in female cardiovascular mortality have been smaller than those in male mortality. It seems as if the factor causing the rise and decline 
Figure 2. Age-standardized mortality (per 100,000) from cardiovascular diseases among males and females aged $35-64$ years in Finland in 1951-78.

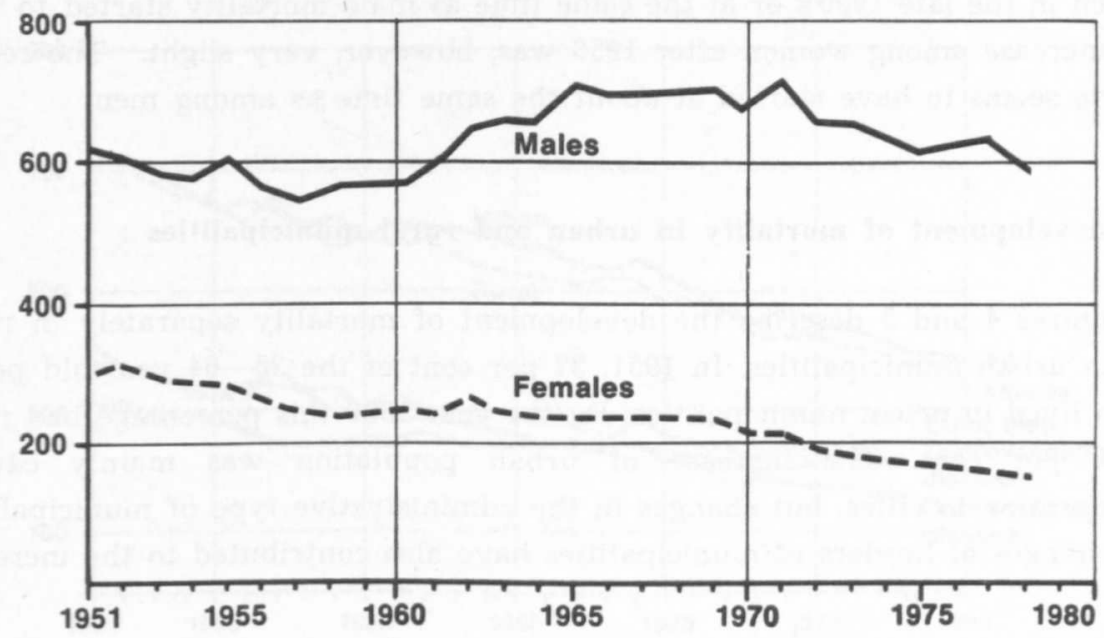

Figure 3. Age-standardized mortality (per 100,000) from other than cardiovascular diseases among males and females aged $35-64$ years in Finland, 1951-78.

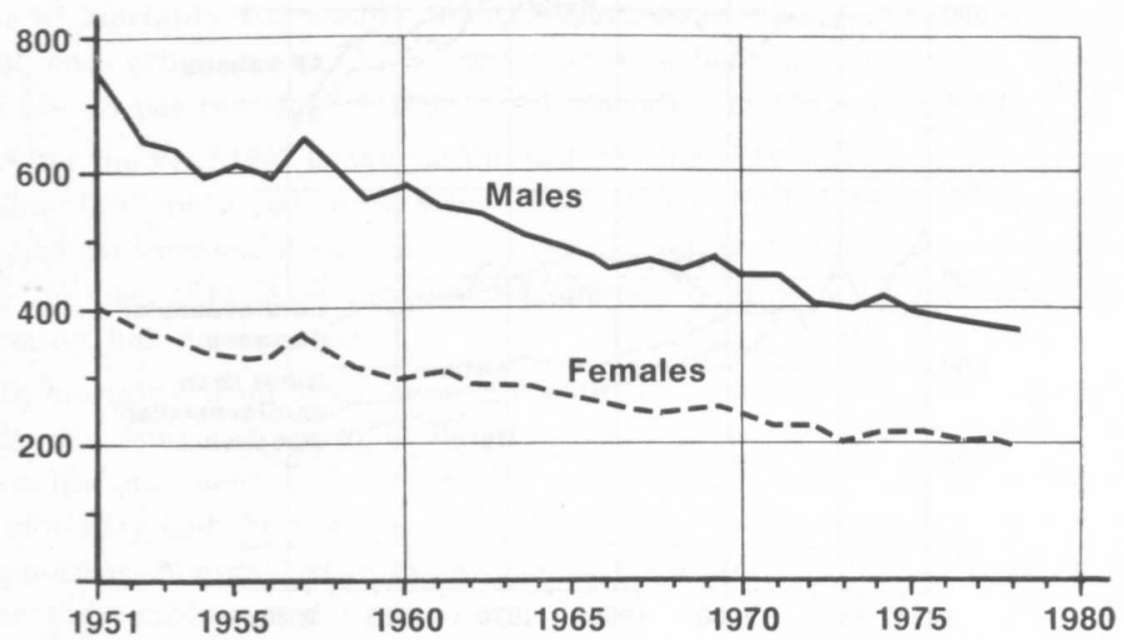


of male mortality would also have influenced female mortality, but the women have been protected in some way, and the effect of the factor has been weakened. The clear declining trend in cardiovascular mortality ended among women in the late 1950 's or at the same time as male mortality started to rise. The increase among women after 1958 was, however, very slight. The recent decline seems to have started at about the same time as among men.

The development of mortality in urban and rural municipalities

Figures 4 and 5 describe the development of mortality separately in rural and in urban municipalities. In 1951, 37 per cent of the 35-64 year-old population lived in urban municipalities. By the year 1980 this percentage had risen to 59 per cent. The increase of urban population was mainly caused by migration to cities, but changes in the administrative type of municipalities and changes of borders of municipalities have also contributed to the increase.

Figure 4. Age-standardized mortality (per 100,000) from all causes, cardiovascular diseases and from other diseases among males aged 3564 in rural and urban municipalities, in Finland 1951-80 (1978).

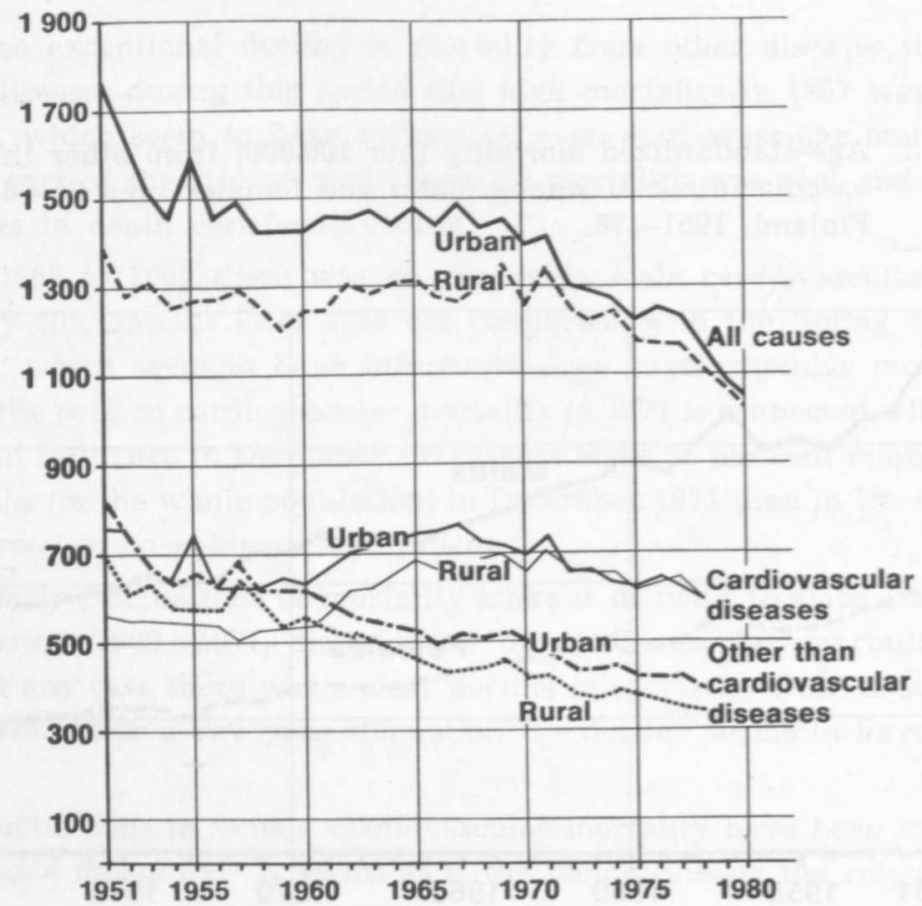


Figure 5. Age-standardized mortality (per 100,000) from all causes, cardiovascular diseases and from other diseases among females aged 35-64 in rural and urban municipalities, in Finland 1951-80 (1978).

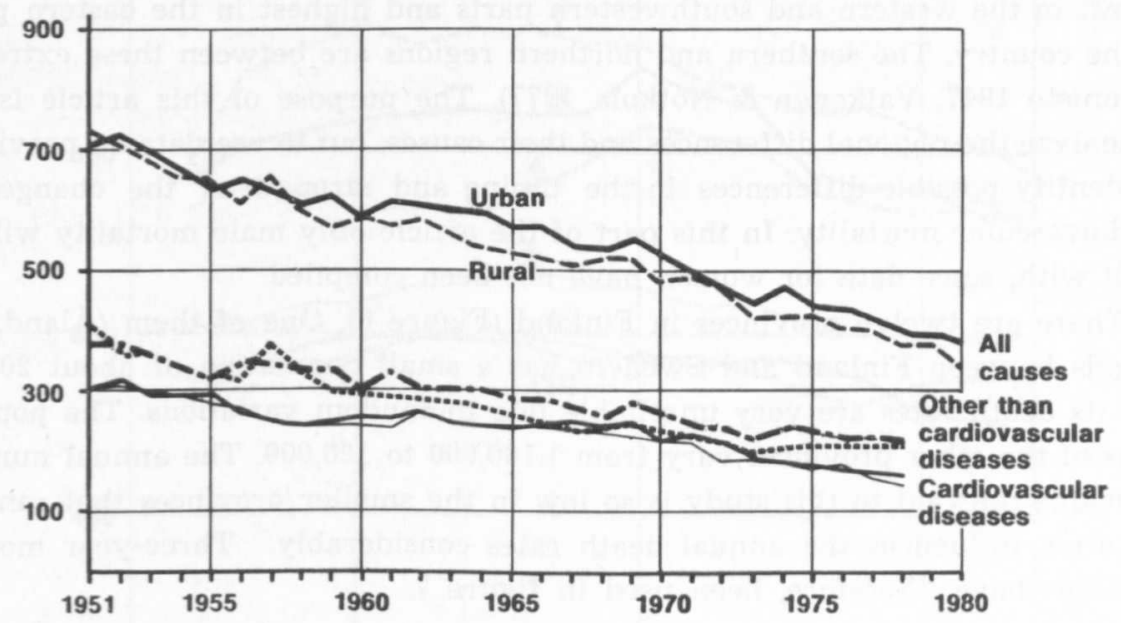

The comparison of figures 4 and 5 immediately shows a surprising difference: the rural-urban mortality differentials are, in general, considerable for men but very small for women.

Among men both cardiovascular mortality and mortality from other diseases were considerably higher in urban than in rural areas in the 1950's. The urban excess mortality for all causes of death varied from 15 to 30 per cent. The increase of male cardiovascular mortality took place simultaneously and at about the same pace in both rural and urban municipalities after 1957. The decline of mortality from other than cardiovascular diseases was also similar in rural and urban areas. As a consequence urban mortality from all causes was 13-18 per cent higher than rural mortality in 1965-67.

After the year 1967 urban cardiovascular mortality started to decline and the decline has continued with some fluctuations until 1978. The development of rural cardiovascular mortality has been different, as there was no decline before the year 1972. As a consequence of these developments the former excess mortality has disappeared.

In mortality from other than cardiovascular diseases the urban excess mortality has remained approximately the same as in the 1950's. Among women there has not been any systematic rural-urban differences in cardiovascular mortality and the changes in mortality have been very similar in rural and urban areas. A slight urban excess mortality can be observed in mortality from other than cardiovascular diseases. 


\section{Regional development of male cardiovascular mortality}

It is well known from several earlier studies that there are great regional differences in mortality from cardiovascular diseases in Finland. Mortality is lowest in the western and southwestern parts and highest in the eastern parts of the country. The southern and northern regions are between these extremes (Kannisto 1947, Valkonen \& Notkola 1977). The purpose of this article is not to analyze the regional differences and their causes, but to use data on provinces to identify possible differences in the timing and strength of the changes in cardiovascular mortality. In this part of the article only male mortality will be dealt with, since data for women have not been compiled.

There are twelve provinces in Finland (Figure 6 ). One of them ( $\AA$ land, the islands between Finland and Sweden) has a small population of about 20,000, and its death rates are very unreliable due to random variations. The populations of the other provinces vary from $1,100,000$ to 180,000 . The annual number of deaths relevant to this study is so low in the smaller provinces that random variation influences the annual death rates considerably. Three-year moving averages have, therefore, been used in figure 7 .

Figure 6. Map of provinces in Finland.

\section{Provinces}

1 Uusimaa

2 Turku \& Pori

3 Åland

4 Häme

5 Kymi

6 Mikkeli

7 Pohjois-Karjala (North Karelia)

8 Kuopio

9 Keski-Suomi

10 Vaasa

11 Oulu

12 Lappi

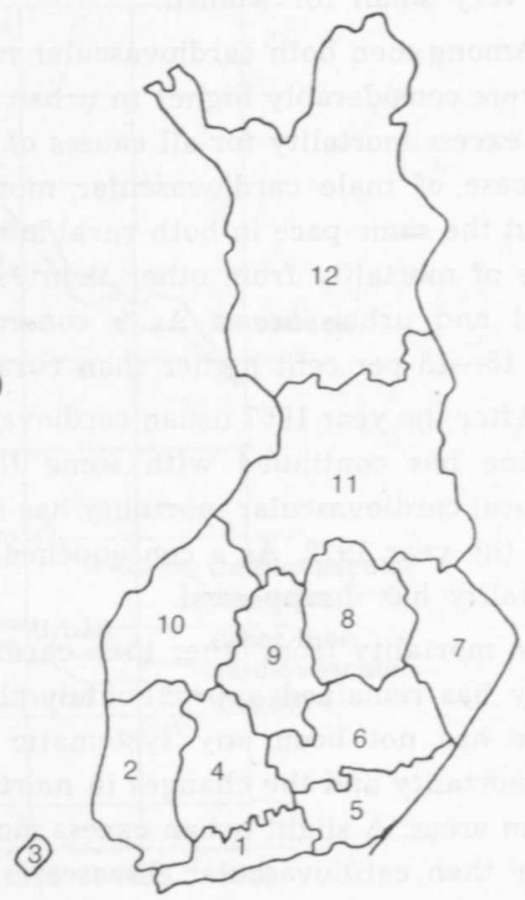


Figure 7. Age-standardized mortality (per 100,000) from cardiovascular diseases among males aged $35-64$ years by province in Finland 1961-1978 (three-year moving averages).
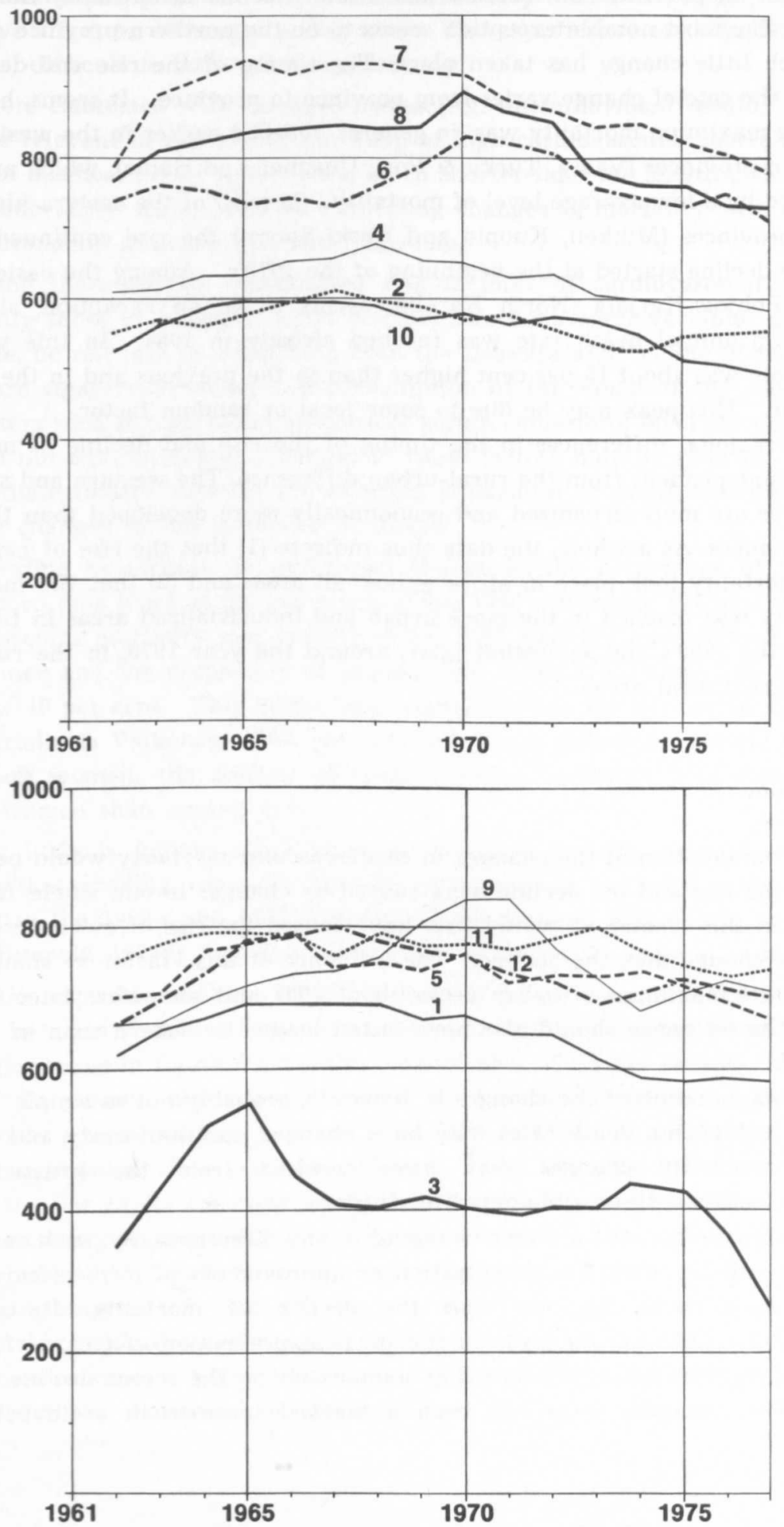
The general pattern of regional differences in male cardiovascular mortality has remained the same during the whole period covered by the study (Figure 7). In almost all provinces an increase and a later decline in mortality can be observed. The most notable exception seems to be the northern province of Oulu, in which little change has taken place. The timing of the rise and decline as well as the rate of change varies from province to province. It seems, however, that the maximum mortality was, in general, reached earlier in the western and southern provinces (Vaasa, Turku \& Pori, Uusimaa and Häme), which are characterized by a low average level of mortality. In most of the eastern high mortality provinces (Mikkeli, Kuopio and Keski-Suomi) the rise continued longer and the decline started at the beginning of the 1970's. Among the eastern provinces Pohjois-Karjala (North Karelia) seems to be an exception, since the maximum annual death rate was reached already in 1964. In this year the death rate was about 15 per cent higher than in the previous and in the following year. This peak may be due to some local or random factor.

The regional differences in the timing of the rise and decline of mortality are not independent from the rural-urban difference. The western and southern provinces are more urbanized and economically more developed than the eastern provinces. As a whole, the data thus indicate (1) that the rise of cardiovascular mortality took place in all or almost all areas and (2) that the maximum mortality was reached in the more urban and industrialized areas in the latter part of the 1960's and somewhat later, around the year 1970, in the rural and more agricultural areas.

\section{Discussion}

The explanation of the changes in cardiovascular mortality would be easiest if both the rise and the decline were caused by changes in one single factor. A change in this "factor $x$ » would first have caused the rise of mortality and an opposite change then the decline. The influence of this "factor $x$ " should have reached its maximum in urban areas about 1967 and somewhat later in rural areas. The influence should also have lasted longer in eastern than in western Finland.

The explanation of the changes is, however, probably not so simple. Several factors influencing death rates may have changed simultaneously and the observed mortality changes may have resulted from the interaction of various factors with possible opposite effects.

It is impossible that a factor changing in one direction only, such as change in the economic structure, urbanization or improvement of medical care, could have caused both the rise and the decline of mortality. It is, however, likely that improvements in the medical prevention and care of cardiovascular diseases have contributed to some extent to the recent decline of mortality. For example, there has been a marked increase in antihypertensive 
treatment and in the proportion of diagnosed hypertensive subjects receiving treatment (Pyörälä \& Valkonen 1981, 51). It is also possible that improvements in the social security system, which have made early retirement easier, have had a positive effect on mortality in the 1970's. The significance of these factors is, however, difficult to evaluate quantitatively.

Factors connected with business cycles (e.g. unemployment) could, in principle, be relevant in explaining the wave of high cardiovascular mortality. The length of business cycles is, however, much shorter than the length of the wave of high mortality. No hypotheses connecting changes in mortality with changes in the economic situation are thus plausible.

Among the so-called »established risk factors" of cardiovascular diseases (especially those of coronary heart disease) two behavioral variables could, in principle, be relevant in explaining both the increase and decline of mortality. These are cigarette smoking and consumption of fat. Some of the established risk factors such as high blood pressure or serum cholesterol level are physiological and not environmental. Changes in these factors may be relevant only as intermediate factors between the external behavioral or environmental causes and the changes in the incidence of disease.

According to surveys no significant change in the percentage of smokers among men took place at the beginning of the 1960's (Rimpelä 1978a), when male cardiovascular mortality rose rapidly. After 1965 smoking has declined rapidly among men and the proportion of smokers has fallen from almost 60 per cent to below 40 per cent. This might have contributed to the decline in mortality (see Martelin \& Valkonen 1980). On the other hand, although smoking increased among women, the decline of cardiovascular mortality was more rapid among women than among men.

Only little is known about changes in regional differences in smoking. It seems that smoking was more common among men in eastern than in western Finland in the 1950's and 1960's. In the 1970's regional differences have vanished (Rimpelä 1978b), but the differences in mortality have not decreased.

Besides cigarette smoking, intake of fat and especially animal fat is considered to be a major factor influencing the incidence of coronary heart disease. The upper curve in figure 8 gives the consumption of fat per person from 1949 to 1978. In general, the consumption of fat has increased in the 1950's and 1960 's; only a small decline occurred from 1955 to 1957 . In the 1970 's, the per capita consumption of fat has not increased. There has been much more variation in the per capita consumption of milk fat than in the consumption of all fats. The consumption of milk fat declined from 1955 to 1957, but then a 31 per cent increase took place in five years. After the peak of the early 1960's the per capita consumption of milk fat has decreased. The third curve of figure 8 shows that most of the changes in milk fat consumption are due to changes in the consumption of butter. The consumption of butter and margarine have fluctuated a lot. For example, the consumption of margarine was only 16 per 
Figure 8. Consumption of all fats and milk fat, meat fat and butter fat (g/ day/person) in Finland in 1949/50-78 (The food balance sheets of the Agricultural Economic Research Institute).

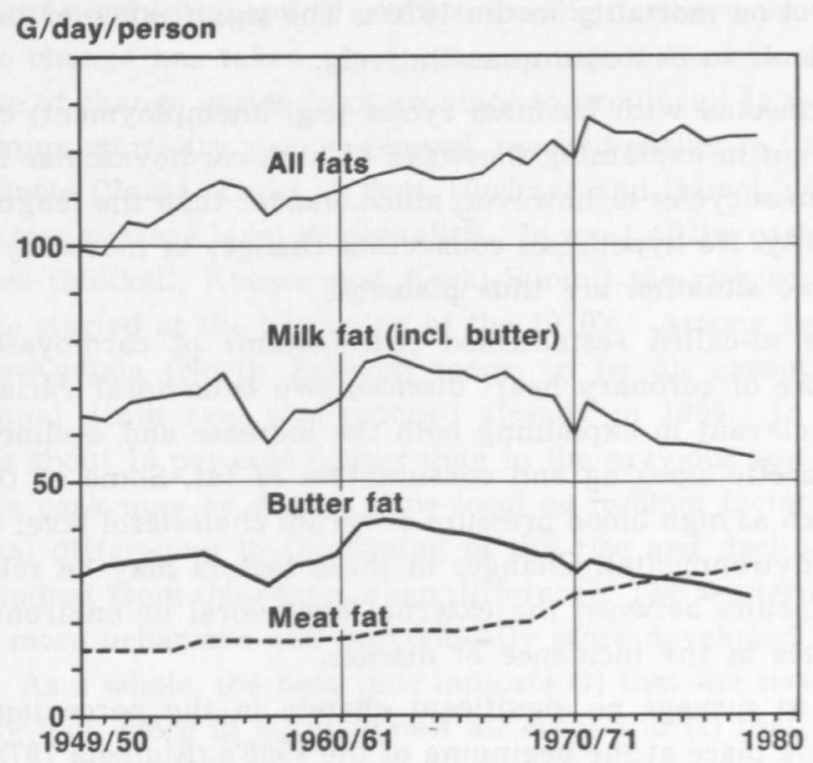

cent in 1962 but 37 per cent in 1978 of the combined consumption of margarine and butter.

The changes in male cardiovascular mortality correlate closely with changes in the consumption of milk fat. Changes in milk fat consumption might thus explain both the rise of cardiovascular mortality in the 1950's and 1960 's and the more recent decline. One has to assume, however, that the increase of milk fat consumption has influenced mortality almost immediately. This may seem unlikely, but it may be noted that, in Norway, cardiovascular mortality declined very rapidly after the food restrictions caused by the German occupation and rose almost immediately after the end of the war. These changes have been assumed to have been due to dietary changes (Ström \& Jensen 1951).

The close association between the changes in consumption of milk fat and mortality from the major cardiovascular disease, ischaemic heart disease in Finland was first presented by Osmo Turpeinen (1978). According to his estimate changes in mortality have followed changes in the consumption of milk fat with a three year lag.

The previous finding concerns the association between milk fat consumption and mortality in the whole country. If data on the changes in the consumption 
of fat were available regionally, the plausibility of the hypothesis about the special role of milk fat could be tested much more reliably. Regional data available to us are, unfortunately, very scanty. Table 1 is based on data from the household surveys carried out by the Central Statistical Office. It covers only the consumption of butter, but the consumption of butter and the total consumption of milk fat are closely correlated. The consumption of butter may thus be used as an indicator of milk fat consumption in general. Due to the small sizes of the samples, the data are not very reliable. Consumption outside the home is not included at all. Despite these weaknesses the main differences are probably correct.

Table 1 indicates that the decline in the per capita consumption of butter was more rapid in urban than in rural areas from 1966 to 1971 . Between 1971 and 1976 the change was of about the same magnitude. These observations are in accordance with the finding of the earlier start of the decline of mortality in urban areas. The regional division used in household surveys is not very suitable for our analysis, since it does not give the figures separately for eastern and western Finland. It indicates, however, that the decline has been greater and earlier in the more industrialized southern Finland than in the country as a whole.

We may conclude that changes in milk fat consumption could have been an important factor causing the rise and decline of cardiovascular mortality among the 35-64 year old Finnish men since the 1950's. The same factor may have influenced the development of female cardiovascular mortality but the influence seems to have been weaker. Improvements in health care and pension systems

$\mathrm{Table} 1$. Home consumption of butter $(\mathrm{kg})$ per person by rural-urban residence and region in 1966, 1971 and 1976.

\begin{tabular}{|c|c|c|c|c|c|c|}
\hline \multirow{2}{*}{ Region } & \multicolumn{3}{|c|}{ Consumption of butter by } & \multicolumn{3}{|c|}{ Index figures $(1966=100)$} \\
\hline & 1966 & 1971 & 1976 & 1966 & 1971 & 1976 \\
\hline Southern Finland 1 & 16.0 & 10.2 & 8.5 & 100 & 64 & 53 \\
\hline Central Finland 2 & 18.9 & 14.6 & 13.2 & 100 & 77 & 70 \\
\hline Northern Finland 3 & 15.6 & 12.9 & 11.1 & 100 & 83 & 71 \\
\hline Whole country & 16.9 & 11.8 & 10.1 & 100 & 70 & 60 \\
\hline Urban municipalities & 14.4 & 8.7 & 7.9 & 100 & 60 & 55 \\
\hline Rural municipalities & 18.9 & 15.1 & 13.7 & 100 & 80 & 72 \\
\hline
\end{tabular}

Sources: Household surveys for 1966, 1971 and 1976. Statistical Surveys No. 51, 55 and 56.

1 Provinces of Uusimaa, Turku \& Pori, Häme, Kymi, and Åland.

2 Provinces of Mikkeli, Pohjois-Karjala, Kuopio, Keski-Suomi, and Vaasa.

3 Provinces of Oulu and Lappi. 
may have contributed to the recent decline to some extent. Decrease of cigarette smoking and as well as other factors not discussed here may also have been relevant.

\section{References}

Havlik, R. J. \& Feinleib, M. (Eds.): Proceedings of the Conference on the Decline in Coronary Heart Disease Mortality. U. S. Department of Health, Education, and Welfare. NIH Publication No. 79-1610, 1979.

Kannisto, V.: Kuolemansyyt väestöllisinä tekijöinä Suomessa. Helsinki 1947.

Martelin, T. \& Valkonen, T.: Tupakointimuutokset ja keski-ikäisten miesten kuolleisuus Suomessa vuosina 1951-1979 sekä laskelmia vuoteen 2000. Department of Sociology, University of Helsinki, Working Papers 19, 1981.

Ovcarov, V. K \& Bystrova, V. A.: Present trends in mortality in the age group 35-64 in selected countries between 1950 and 1973. World Health Statistics Quarterly 31 (3): $208-346,1978$.

Pyörälä, K. \& Valkonen, T.: The high ischaemic heart disease mortality in Finland. International comparisons, regional differences, trends and possible causes. Skandia International Symposia. Medical Aspects of Mortality Statistics: 37-57, 1981.

Rimpelä, M.: Aikuisväestön tupakointitapojen muutosten seurantakatsaus Suomen Gallup Oy:n toteuttamien kyselytutkimusten tuloksiin ja seurantajärjestelmän kehittämiseen. Sosiaalilääketieteellinen aikakauslehti 15 (3), 1978a.

Rimpelä, M.: Aikuisväestön tupakointitavat Suomessa 1950-1970-luvuilla. Kansanterveystieteen julkaisuja M 40, 1978b.

Strøm, A. \& Jensen, R. A.: Mortality from circulatory diseases in Norway 1940-1945. Lancet I: $126-129,1951$.

Turpeinen, O.: Rasvat uhkana sydämelle. Helsingin Sanomat 17. 4. 1978.

Valkonen, T. \& Niemi, M.-L.: Miesten kuolleisuuden kehitys läänin ja kuolemansyyn mukaan Suomessa $1961-75$ (The development of male mortality by county and cause of death in Finland in 1961-75, summary and table headings in English). Department of Sociology, University of Helsinki, Working Papers No 12, 1980.

Valkonen, T. \& Notkola, V.: Social environment and natural environment in relation to ischaemic heart disease mortality in Finland. Nordic Council Arct. Med. Res. Rep. No. 19: 95-100, 1977. 